\title{
SENSE OF COHERENCE AND HEALTH-RELATED BEHAVIOUR AMONG UNIVERSITY STUDENTS - A QUESTIONNAIRE SURVEY
}

\author{
Monika Binkowska-B ury, Paweł J anuszewicz \\ Institute of Public Health, Medical Department, University of Rzeszow, Poland
}

\begin{abstract}
SUMMARY
The aim of this study is to evaluate the relation between a sense of coherence and intensity of health-related behaviour among 521 Polish university students. The study was conducted using validated instruments with two questionnaires: Antonovsky's SOC-29 and the Inventory of Health-Related Behaviour. The mean value of $\mathrm{SOC}$ amounted to 125.2. More than half of the studied group were characterized by the average level of SOC. No statistical differences were found between the faculty of study and $S O C \quad(p=0.107)$. A low intensity of health-related behaviour characterized a large group of students. Students of particular faculties differ among themselves in a statistically significant way in the level of health-related behaviour $(p=0.015)$. SOC is related to healthy behaviour $(p<0.001)$. University students are often characterized by an average level of $S O C$ and a low intensity of health-related behaviour. Medical students are characterized by higher level of health-related behaviour in comparison with humanistic and science students. SOC correlates positively with a tendency to health-related behaviour. The higher the level of coherence, the higher is the tendency towards pro-health behaviour.
\end{abstract}

Key words: lifestyle orientation, pro-health conduct, students

Address for correspondence: M. Binkowska-Bury, Institute of Public Health, Medical Department, University of Rzeszow, Warzywna 1, 35-328 Rzeszow, Poland. E-mail: monika.binkowska@yahoo.com

\section{INTRODUCTION}

In recent years, health-related behaviours have become the fundamental area of interest of practitioners and scientists of many disciplines. A growing body of researches and government programmes considering health has been focused on individual or group behaviours (1). It is seen in the literature that many authors have investigated the prevalence or changes of students' health-related behaviour (2) and their knowledge about it (3-5). In general, young people are aware of the risks and harmful effects of tobacco smoking, alcohol consumption, lack of proper nutrition habits, or low levels of physical activity (6-7); however a lack of strong motivation has very often hindered taking proper decisions concerning health. It is therefore important to continue the research in the scope of this topic among young people.

According to the professional literature, health-related behaviours and lifestyles are related to the salutogenic concept of health. The main concept of Antonovsky's theory says that each person has an individual predisposition which makes him or her more or less resistant to stressful factors with which he or she is confronted in everyday life. Antonovsky precisely identifies those predispositions determined by him as a sense of coherence (SOC) "a global orientation that expresses the extent to which one has a pervasive, enduring though dynamic feeling of confidence that (comprehensibility) the stimuli deriving from one's internal and external environments in the course of living are structured, predictable and explicable; (manageability) the resources are available to one to meet the demands posed by these stimuli; and (meaningfulness) these demands are challenges, worthy of investment and engagement. According to him SOC guarantees efficient methods of coping with stress and has a positive influence on health-related behaviour. Therefore in a significant way it also helps to keep a good state of health. SOC consists of three components: meaningfulness, comprehensibility, and manageability in individual life, and each of these elements can be scalable and evaluated with an appropriate scale (8-10).

For many years, the researches on SOC as a health indicator have provided evidence of an association between high SOC and different aspects of health. Many earlier studies have proved that SOC positively correlates with positive psychological symptoms of health such as well-being (11-13), self-esteem (13-14), life satisfaction (15), and quality of life (16-17), proving that high SOC is strongly related to general positive psychological symptoms and people with high SOC are more likely to prefer healthier lifestyles.

At the same time, many studies demonstrated that a low SOC is associated with negative psychological symptoms of health such as anxiety (17), depression (18), burnout (13, 19-20), anger, demoralization, hostility, hopelessness, perceived stressors, and post-traumatic stress disorder (21-22). Earlier studies exploring the role of SOC in stress symptoms have shown that people with high levels of SOC experience fewer stress symptoms and cope more efficiently with stress than people with lower SOC (23-24). Moreover, studies examining the relation of SOC with depres- 
sive symptoms and mental health have proved that higher SOC is associated with lower levels of depression and anxiety (18).

Research conducted by Wainwright and Surtees showed that individual differences in SOC are associated with healthy lifestyle choices independently of social class and education. Despite the gender, people with strong SOC were less likely to be current smokers, less likely to be physically inactive, and reportedly consumed more fruits, vegetables, and fibre, but more alcohol, than participants who reported weak SOC (25).

Studies on SOC and subjective health (26-28) have revealed an association between a strong SOC and good subjective health. It was demonstrated that low SOC is related to poor perceived health and low levels of social and emotional support.

Various studies have shown that strong SOC correlates positively with treatment results and vocational rehabilitation outcomes. It was proven that people with high SOC had a relatively high belief in vocational return (29) and a high index of active management and emotional acceptance of disease (30). Moreover, although controversial, it was confirmed that a strong SOC is associated with a reduction in mortality from all causes (31-32).

Researches dedicated to SOC and its impact on human health have been carried out only recently and are the current subject of many international and Polish studies; nevertheless there are still not many reports linking SOC with patterns of health-related behaviour among young people. Originally, SOC was studied in adults but lately several studies have been conducted among children and young people.

Studies conducted by Torsheim et al. (2001) on the role of SOC in the relationship between adolescent school-related stress and subjective health complaints have revealed that association. It was demonstrated that while stress grew weaker with age, at the same time the direct association between SOC and health complaints grew stronger. Therefore, according to the study it might be assumed that in younger age-groups SOC may potentially be a salutogenic factor in adolescents' adaptation to school-related stress (33).

Studies carried out by Togari et al. (2007) among students ascertained that SOC is a predictor of subsequent health and wellbeing for subjects in their adolescence (34). The demonstrated impact of SOC on subsequent well-being is consistent with Antonovsky's theory, according to which childhood and adolescence are crucial stages in life, assuming that life experiences participate in shaping SOC in later phases of life.

According to Antonovsky, SOC is shaped, reinforced, and refined throughout one's life and tends to become relatively stable by age 30 , and therefore it seems important to investigate its development among young people as in the future it might be important in shaping health-related behaviours among young people (8).

The aim of this study is to evaluate the relation between SOC and intensity of health-related behaviours among university students.

\section{MATERIALS AND METHODS}

The full study was preceded by a pilot study conducted among 50 students of the University of Rzeszow. The full study was conducted between January and June 2006 among 555 students of two major universities of Podkarpackie Region, Poland: the University of Rzeszow and the Technical University. The students represented the following faculties: Polish and English philology, nursing, midwifery, mathematics, and physics. The study population was purposefully chosen and restricted to the last years of students of science, humanities, and medicine. This allowed for unification of the study population in terms of age and university experience and also provided a cross section between different faculties of study. The analysed sample provided a full representation of young academic experience among students who had adapted to the particular lifestyle and had adopted certain patterns and behaviours. The selected sample of 555 people received questionnaires. Out of the 536 replies, 521 were qualified as correctly filled-in, which constitutes $93.8 \%$ of the assumed sample. The study population included:

- 183 (35\%) Technical University students representing scientific faculties such as mathematics and physics,

- 338 (65\%) University of Rzeszow students representing humanistic faculties, namely Polish and English philology, and medical faculties, such as nursing and midwifery.

Among the studied population the majority were women (75.6\%). Half of the respondents were aged 20-21 years while some were older. More than a half of the respondents were from rural areas (56.3\%). Almost half (45.1\%) of the population described their financial situation as relatively good, $30.8 \%$ of respondents described their situation as good, $16.6 \%$ as difficult, and $3.7 \%$ as very good.

The survey was conducted by means of a diagnostic survey with the use of A. Antonovsky's Sense of Coherence Questionnaire SOC-29 and the Inventory of Health-Related Behaviour (Zygfryd Juczynski’s IZZ).

\section{The Sense of Coherence Questionnaire SOC-29}

The Polish SOC scale was prepared in accordance with methodological recommendations and was translated both ways by psychologists-researchers and authorized by Antonovsky. The scale was created in 1993 (35).

In order to conduct a comparative analysis of the mean values of SOC and its components, three separate study groups with low, average, and high SOC were distinguished. Such division was conducted according to the values of the upper and lower quartiles, which amounted to scores 113 and 136, respectively. The following distribution rule was used:

- low SOC: scores less than 113

- average SOC: scores from 113 to 136

- high SOC: scores above 136

In the population the division was done in the proportion 1 to 2 to 1 and it was kept in a variety of studies.

\section{Inventory of Health-Related Behaviour (Zygfryd Juczynski’s IZZ)}

The Inventory of Health-Related Behaviour (Zygfryd Juczynski's IZZ) was used in order to establish the general intensity of pro-health behaviour as well as the intensity of the four categories of pro-health behaviours: proper nutrition habits (type of foods, well-balanced diet), prophylaxis (health recommendations, health and disease information), positive attitude (psychological factors 
Table 1. Level of sense of coherence according to the values of upper and lower quartiles

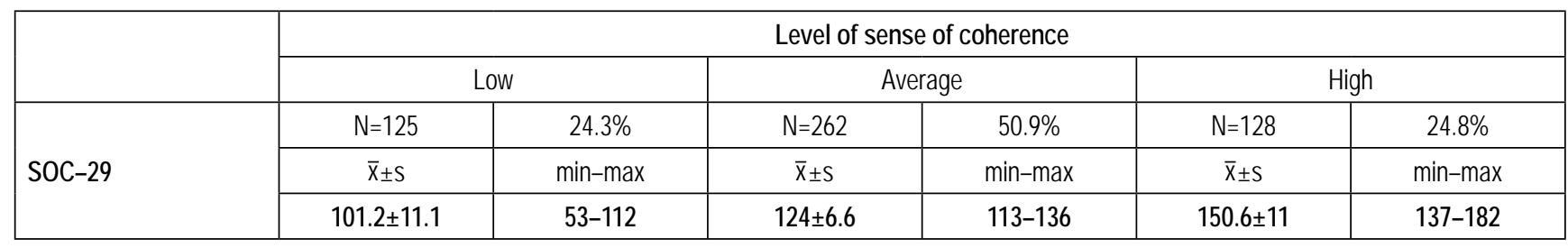

Table 2. Intensity of pro-health behaviour related with health: the Inventory of Health Behaviours (IZZ)

\begin{tabular}{|l|c|c|c|c|c|c|c|c|}
\hline Faculty of study & \multicolumn{2}{|c|}{$\begin{array}{c}\text { Humanistic } \\
\text { N=166 }\end{array}$} & \multicolumn{2}{c|}{$\begin{array}{c}\text { Science } \\
\text { N=178 }\end{array}$} & \multicolumn{2}{c|}{$\begin{array}{c}\text { Medical } \\
\text { N=159 }\end{array}$} & $\begin{array}{c}\text { Total } \\
\text { N=503 }\end{array}$ \\
\hline Level of IZZ & $\mathbf{N}$ & $\%$ & $\mathbf{N}$ & $\%$ & $\mathbf{N}$ & $\%$ & $\mathbf{N}$ & $\%$ \\
\hline Low & 77 & 46.4 & 100 & 56.2 & 69 & 43.4 & 246 & 48.9 \\
\hline Average & 74 & 44.6 & 58 & 32.6 & 61 & 38.4 & 193 & 38.4 \\
\hline High & 15 & 9.0 & 20 & 11.2 & 29 & 18.2 & 64 & 12.7 \\
\hline$p$ & \multicolumn{9}{|c|}{0.015} \\
\hline
\end{tabular}

Table 3. Comparison of average IZZ values and faculties of study

\begin{tabular}{|l|c|c|c|c|c|c|c|}
\hline Faculty of study & \multicolumn{2}{|c|}{$\begin{array}{c}\text { Humanistic } \\
\mathrm{N}=166\end{array}$} & \multicolumn{2}{c|}{$\begin{array}{c}\text { Science } \\
\mathrm{N}=179\end{array}$} & \multicolumn{2}{c|}{$\begin{array}{c}\text { Medical } \\
\mathrm{N}=160\end{array}$} \\
\hline IZZ cathegories & $\overline{\mathrm{x}}$ & $\mathrm{S}$ & $\overline{\mathrm{x}}$ & $\mathrm{S}$ & $\overline{\mathrm{x}}$ & $\mathrm{S}$ & $\mathrm{P}$ \\
\hline Proper eating habits & 18.1 & 4.49 & 16.7 & 4.34 & 19 & 4.15 & $<0.001$ \\
\hline Prophylactic behaviour & 17.7 & 4.72 & 16.6 & 4.82 & 20.7 & 4.65 & $<0.001$ \\
\hline Positive attitudes & 20.4 & 4.14 & 20.3 & 4.14 & 20.9 & 4.21 & 0.037 \\
\hline Health practices & 19.6 & 4 & 18.7 & 4.3 & 18.6 & 4.3 & 0.050 \\
\hline Total of IZZ & 75.8 & 12.6 & 72.3 & 14.2 & 79.2 & 14 & $<0.001$ \\
\hline
\end{tabular}

such as avoiding too strong emotions, stress, anxiety, and depressive situations), and pro-health practices (sleep habits, recreation, and physical activity). The Inventory of Health-Related Behaviour was created by Zygfryd Juczynski in 1997 and includes 24 statements describing different behaviours related to health. Taking into consideration the frequency of individual behaviours indicated by scientists, the general intensity of health-related behaviour and the intensities of four categories are estimated. The Inventory is intended to examine healthy and sick adults. Used with other types of diagnostic surveys it may be helpful in planning prophylaxis activities, determining the direction of behaviours modification, and monitoring changes in health practices (36).

The gathered data were statistically prepared by means of a statistical package. For the purpose of the survey students were divided according to the faculty of study. The selection of the method of analysis was determined by the research problems. Types of descriptive statistics such as mean, standard deviation (SD), median, upper and lower quartile, and highest and lowest value, the $\chi^{2}$ test, and methods of analysis of variance were used for statistical analysis.

Participation in the survey was both voluntary and anonymous and the research material was treated confidentially. The students were given instructions in a covering letter, followed by the questionnaire, and before the survey they were informed about the procedure and the purpose of study. Codes were used to identify the faculty of study of the examined group. Return of the completed questionnaires was accompanied by the confirmation of participation agreements.

\section{RESULTS}

The mean value of SOC was 125.2 and the standard deviation was 19.5. The mean values of the sense of comprehensibility ( $\bar{x} 42.5$ s -8.1), sense of manageability ( $\bar{x} 44.7$ s -7.9 ), and sense of meaningfulness ( $\bar{x} 37.9 \mathrm{~s}-7.4$ ) were determined.

An average level of SOC was shown by $50.9 \%$ of students (minimal value: 113; maximal value: 136). A high level of SOC was shown by $24.8 \%$ of students (minimal value: 137 ; maximal value: 182). A low level of SOC was shown by $24.3 \%$ (minimal value: 53; maximal value: 112 ) (Table 1 ).

The comparative analysis of mean values of SOC and its components showed that the examined university students do not differ among themselves in SOC ( $\mathrm{p}=0.107)$, sense of manageability ( $\mathrm{p}=0.495)$, and sense of meaningfulness ( $\mathrm{p}=0.067)$. However, they differ in the sense of comprehensibility at a statistically significant level $(p=0.023)$. The medical students were found to have a higher sense of comprehensibility $(\mathrm{SD}=43.5)$ than the students of science and the humanities ( $\mathrm{SD}=41.2$ ).

In general, $48.9 \%$ of the students were characterized by a low intensity of pro-health behaviour, whereas among $38.4 \%$ it is described as average. Only $12.7 \%$ of the respondents declared 


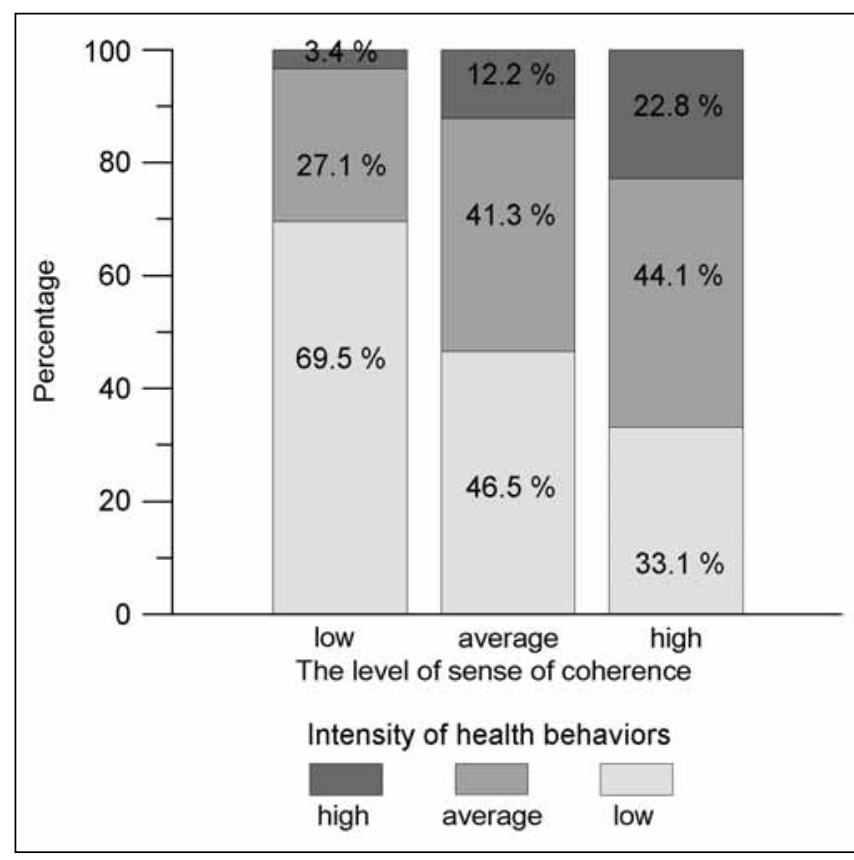

Fig. 1. The level of sense of coherence and the intensity of health behaviours according to the Inventory of Health Behaviours (IZZ).

a high intensity of pro-health behaviour. A significant difference between the faculties ( $p=0.015$ ) was found. The highest percentage of health-related behaviour was found among students of the medical faculties (18.2\%), while over half (56.2\%) of science students were characterized by a low intensity of health-related behaviour (Table 2).

Students of particular faculties differ significantly as far as the general intensity of health-related behaviour $(p<0.001)$ is concerned. They also differ in respect of proper diet $(\mathrm{p}<0.001)$ and prophylaxis $(\mathrm{p}<0.001)$. In the above-mentioned categories, the highest scores were found among students of medical faculties (mean=79.2; $\mathrm{SD}=14$ ), medium scores were found among students of humanities (mean=75.8; $\mathrm{SD}=12.6$ ), and the lowest among the students of science (mean=72.3; $\mathrm{SD}=14.2$ ). At the same time, no statistically significant differences were found in relation to the remaining categories: positive attitude $(\mathrm{p}=0.372)$ and pro-health practice $(\mathrm{p}=0.050)$. This may mean that irrespective of faculty, all students attempt to avoid strong emotions, stress, anger, fear, and depressing situations, and all lead a balanced family life and see their doctor regularly (Table 3).

The level of SOC significantly influences the intensity of health behaviour amongst the studied group of students. The result of the test of independence of $\chi^{2}$ amounts to $p<0.001$. The dependence is logically oriented. The higher the level of SOC, the higher the intensity of behaviours which favour health in all categories of the Inventory of Health Behaviours (IZZ), that is:

- proper eating habits: the students pay attention to the kind of food eaten in terms of the amount and quality;

- prophylactic behaviour: the students obey health recommendations and express a desire to obtain more information about their health and illness;

- health practices: the students choose active forms of leisure and use sleep rationally;
- positive attitudes: students avoid too strong emotions, stress, tension, and situations which have a depressing effect on them (Fig. 1).

A detailed analysis considering the relation between SOC and the intensity of health-related behaviour (IZZ) according to faculty division indicates that the level of SOC correlates positively with the tendency to show behaviours which favour health in the case of the students of all fields of study examined. However, the highest relation was observed in the medical students $(p<0.001)$, followed by science students $(p=0.012)$ and humanities students $(\mathrm{p}=0.015)$.

\section{DISCUSSION}

According to Antonovsky SOC is an essential factor conditioning the type of health-related behaviour. In the author's opinion, the higher the level of SOC, the higher is the tendency towards showing pro-health behaviours (9). The period of university study might significantly influence the choice of behaviour in the context of health. Most often it is related to specific social life conditions such as weekly and semestral rhythm of work, credits, tests, exams, and relationships with tutors and peers (2).

The results of this study showed that among the studied group the mean value of SOC amounts to 125.2 and more than half of students showed an average level of SOC. In the studies carried out among students published in world literature, different results for SOC values were obtained $(14,34,37)$.

The results closest to those established by this study were obtained by Lam (2007), who examined 122 American students of Vietnamese origin, whose SOC was estimated at 124.38 (14). A slightly higher value of SOC, 127.55, was found among American Chinese in an investigation by Ying (2007) (37). However, Japanese students were characterized by a lower value of SOC, 117.9 , and a definitely higher value, 142.5, was found among European students (38). The above mentioned data indicate the unambiguous differentiation of the level of SOC among students, which in turn is in accordance with Antonovsky's concept, according to which SOC is shaped, reinforced, and refined throughout one's life, and a significant meaning is attributed to the conditions in which the child grows up and develops as a young person. The essential role of the influence of socio-cultural context (over a long period of time) and the pattern of life experience are shown to be very important in the establishment of SOC.

In international literature there are some studies investigating the changes of SOC in groups of young people (39-40). Studies carried out by Kuuppelomäki and Utriainen in the years 1996-1999, considering the assessment of SOC at the beginning of study, its continuation, and in the third year of study among Finnish students, showed that for the majority of young people, there was no change from the baseline SOC at the end stage of study. SOC had weakened only in the case of a few students, and one third of students strengthened their SOC (40).

The majority of studies conducted all around the world focus on the relationship between high SOC and a state of good health $(8,9)$. In this context, undertaking educational activities aiming to shape strong SOC among young people would be an important element of the education of young society for the benefit of 
conscious choices about health-related behaviour. In the Polish studies, despite a growing interest in these issues, relatively few reports combining SOC with patterns of health behaviours are found, while studies on this subject conducted on the population of young people are almost not present at all.

In the present study almost half of the university students (48.9\%) were characterized by low intensity of pro-health behaviour and almost every third student had an average intensity. Only $12.7 \%$ of the studied groups were distinguished by high levels of such behaviours; in the greatest numbers they were the students of nursing and midwifery. Over half of the students of science were characterized by low levels of pro-health behaviours. The students differed among themselves in the intensity of health behaviours. The medical students showed the strongest tendency towards pro-health behaviours, which was understandable on account of the high level of saturation of topics concerning health and illness in the training programme. It seems that results obtained in the present study are similar and indicate the need to undertake pro-health activities among students.

The analysis of the relation between SOC and its components (levels of comprehensibility, manageability, meaningfulness) and patterns of health behaviours among university students have proven that such an association exists. The higher the level of SOC, the higher is the tendency towards undertaking pro-health behaviour. The present study allows us to state that the students with a strongly developed SOC more frequently paid attention to the kind of food eaten in terms of the amount and the quality; they also obeyed health recommendations more frequently, chose active forms of leisure, used sleep rationally, avoided too strong emotions, stress, and situations which had a depressing effect on them, and also handled stress better. The studied group with a high level of SOC undertook anti-health behaviours much less in comparison to the students with a low level of SOC, for example in terms of alcohol consumption, smoking, and the taking of medicines (painkillers, tranquilizers, sleeping pills). In the international research on young people, abnormal behaviours are characteristic for the majority of the population, where among groups of students studied, people who smoke constitute $23.6-58.7 \%$ and those who consume alcohol constitute 43-52\% (41-42). What is more, heath promoting behaviours are relatively unpopular: regular physical activity at least three times a week is performed by approximately $28.4 \%$ of young people and a well-balanced diet is observed by $33.6 \%$ (43). A detailed comparative analysis with other scientific works is quite difficult due to different survey questions formulations and different interpretations.

Quite interesting data in that scope were presented by Kuuppelomäki and Utriainen (2003) (40). Their study considering the change in SOC among health care students showed that health-related behaviours such as physical activity, smoking, and drinking alcohol were not associated with changes in intensity of SOC.

The present study clearly demonstrates that SOC has a positive affect on undertaking health-related behaviour and a favourable influence on the health of young people. Antonovsky's salutogenetic model is quite a new concept which is extremely important to fields of science such as health psychology and health promotion. The author of this concept, being against shifting the responsibility for health to the lifestyle, omitted lengthy deliberations on the relations, which means that this subject is still open to further research and deep analyses $(8,44)$. This fact forces researchers who deal with these issues to continue studies which will allow them to present unambiguously the relations between the level of SOC and pro-health behaviours and help to provide a detailed identification of factors related with SOC during the study period. The results gained in this study prove that such relations exist and that they can have a very essential theoretical and practical meaning. SOC is one of the most important resources of the individual which protect against the destructive impact of difficult situations. Therefore, in the process of teaching, it is worth undergoing and broadening experience which will be coherent and intelligible and will strengthen SOC among students.

\section{CONCLUSIONS}

1. The mean value of SOC amounted to 125.2. University students are often characterized by an average level of SOC.

2. A low level of pro-health behaviour is characteristic for the large group of students studied. The students of particular fields of studies differ among themselves in statistical significance in terms of the level of health behaviours (IZZ). The medical students are characterized by a high level of pro-health behaviour such as correct eating habits, prophylactic behaviours, and positive attitudes in comparison with the students of humanities and science.

3. SOC correlates positively with the tendency towards healthrelated behaviour. The higher the level of coherence, the higher is the tendency towards practising pro-health behaviours.

\section{Limitation}

The participants were recruited from two local universities in the Region of Podkarpackie, Poland, which is reflected in the analysis and results. It is recommended in the future to examine the relation between the level of sense of coherence and patterns of health-related behaviour among students of other universities in Poland.

\section{Acknowledgement}

Funding: Financial support is gratefully acknowledged from Institute of Nursing and Midwifery, Medical Department, University of Rzeszow, Poland.

Ethical approval: This study was not subject to ethical review.

Contribution: The authors express their sincere appreciation to Maja Wolan for her invaluable assistance and language help.

\section{REFERENCES}

1. Healthy People 2010 [Internet]. Rockville: U.S. Department of Health and Human Services; 2000 [cited 2010 Mar 31]. Available from: http:// www.healthypeople.gov/.

2. Steptoe A, Wardle J, Cui W, Bellisle F, Zotti AM, Baranyai R, et al. Trends in smoking, diet, physical exercise, and attitudes toward health in European university students from 13 countries, 1990-2000. Prev Med. 2002 Aug;35(2):94-104.

3. Kear ME. Psychosocial determinants of cigarette smoking among college students. J Community Health Nurs. 2002;19(4):245-57.

4. Al-Ansari JM, Honkala S. Gender differences in oral health knowledge and behavior of the health science college students in Kuwait. J Allied Health. 2007;36(1):41-6.

5. Ford MA, Bass MA, Keathley R. Osteoporosis knowledge and attitudes: a cross-sectional study among college-age students. J Am Coll Health. 2007 Jul-Aug;56(1):43-7. 
6. Carroll SL, Lee RE, Kaur H, Harris KJ, Strother ML, Huang TT. Smoking, weight loss intention and obesity-promoting behaviors in college students. J Am Coll Nutr. 2006 Aug;25(4):348-53.

7. Binkowska-Bury M, Motyka $\mathbf{M}$. The sense of coherence and risky behaviors among students of the Politechnika Rzeszowska. Pol J Envir Stud. 2007;16(5C):51-6.

8. Antonovsky A. Unraveling the mystery of health: how people manage stress and stay well. San Francisco: Jossey-Bass Publishers; 1987.

9. Antonovsky A. Can attitudes contribute to heath? Advances. 1992;8(4):3349.

10. Antonovsky A. The structure and properties of the sense of coherence scale. Soc Sci Med. 1993 Mar;36(6):725-33.

11. Larsson G, Kallenberg KO. Sense of coherence, socioeconomic conditions and health: interrelationships in a nation-wide Swedish sample. Eur J Pub Health. 1996;6(3):175-80.

12. Gana K. Is sense of coherence a mediator between adversity and psychological well-being in adults? Stress Health. 2001;17(2):77-83.

13. Kalimo R, Pahkin K, Mutanen P, Topipinen-Tanner S. Staying well or burning out at work: work characteristics and personal resources as longterm predictors. Work Stress. 2003 Jan;17(2):109-22.

14. Lam BT. Impact of perceived racial discrimination and collective selfesteem on psychological distress among Vietnamese-American college students: sense of coherence as mediator. Am J Orthopsychiatry. 2007 Jul;77(3):370-6

15. Buddeberg-Fischer B, Klaghofer R. Development of body image in adolescence. Prax Kinderpsychol Kinderpsychiatr. 2002 Nov;51(9):697-710. (In German.)

16. Svartvik L, Lidfeldt J, Nerbrand C, Samsioe G, Scherstén B, Nilsson PM. Dyslipidaemia and impaired well-being in middle-aged women reporting low sense of coherence. The Women's Health in the Lund Area (WHLA) Study. Scand J Prim Health Care. 2000 Sep;18(3):177-82.

17. Nesbitt BJ, Heidrich SM. Sense of coherence and illness appraisal in older women's quality of life. Res Nurs Health. 2000 Feb;23(1):25-34.

18. Farruggia SP, Chen C, Greenberger E, Dmitrieva J, Macek P. Adolescent self-esteem in cross-cultural perspective: testing measurement equivalence and a mediation model. J Cross Cult Psychol. 2004;35(6):719-33.

19. Yinga YW, Leeb PA, Tsaic JL. Attachment, sense of coherence, and mental health among Chinese American college students: variation by migration status. Int J Intercult Relat. 2007 Sep;31(5):531-44.

20. Söderfeldt M, Söderfeldt B, Ohlson CG, Theorell T, Jones I. The impact of sense of coherence and high-demand/low-control job environment on self-reported health, burnout and psychophysiological stress indicators. Work Stress. 2000 Jan;14(1):1-15.

21. Tselebis A, Moulou A, Ilias I. Burnout versus depression and sense of coherence: study of Greek nursing staff. Nurs Health Sci. 2001 Jun;3(2):69-71.

22. Eriksson M, Lindström B. Antonovsky's sense of coherence scale and the relation with health: a systematic review. J Epidemiol Community Health. 2006 May;60(5):376-81.

23. Karlsson I, Berglin E, Larsson PA. Sense of coherence: quality of life before and after coronary artery bypass surgery- a longitudinal study. J Adv Nurs. 2000 Jun;31(6):1383-92.

24. Albertsen K, Nielsen ML, Borg V. The Danish psychosocial work environment and symptoms of stress: the main, mediating and moderating role of sense of coherence. Work Stress. 2001 Jul;15(3):241-53.

25. Cohen O, Savaya R. Sense of coherence and adjustment to divorce among Muslim Arab citizens of Israel. Eur J Pers. 2003;17(4):309-26.

26. Wainwright N, Surtees PG, Welch AA, Luben RN, Khaw KT, Bingham SA. Healthy lifestyle choices: could sense of coherence aid health promotion? J Epidemiol Community Health. 2007;61(10):871-6.

27. Lundman B, Norberg A. The significance of a sense of coherence for subjective health in persons with insulin-dependent diabetes. J Adv Nurs. 1993 Mar;18(3):381-6.
28. Suominen S, Blomberc H, Helenius H, Koskenvuo M. Sense of coherence and health -does the association depend on resistance resources? A study of 3115 adults in Finland. Psychol Health. 1999 Sep;14(5):937-48.

29. Nilsson B, Holmgren L, Westman G. Sense of coherence in different stages of health and disease in northern Sweden - gender and psychosocial differences. Scand J Prim Health Care. 2000 Mar;18(1):14-20.

30. Melin R, Fugl-Meyer AR. On prediction of vocational rehabilitation outcome at a Swedish employability institute. J Rehabil Med. 2003 Nov;35(6):284-9.

31. Sandén-Eriksson B. Coping with type-2 diabetes: the role of sense of coherence compared with active management. J Adv Nurs. 2000 Jun;31(6):1393-7.

32. Surtees P, Wainwright N, Luben R, Khaw KT, Day N. Sense of coherence and mortality in men and women in the EPIC-Norfolk United Kingdom prospective cohort study. Am J Epidemiol. 2003 Dec 15;158(12):1202-9.

33. Poppius E, Tenkanen L, Kalimo R, Heinsalmi P. The sense of coherence, occupation and the risk of coronary heart disease in the Helsinki Heart Study. Soc Sci Med. 1999 Jul;49(1):109-20.

34. Torsheim T, Aaroe LE, Wold B. Sense of coherence and school-related stress as predictors of subjective health complaints in early adolescence: interactive, indirect or direct relationships? Soc Sci Med. 2001 Sep;53(5):603-14.

35. Togari T, Yamazaki Y, Nakayama K, Shimizu J. Development of a shor version of the sense of coherence scale for population survey. J Epidemiol Community Health. 2007 Oct;61(10):921-2.

36. Koniarek J, Dudek B, Makowska Z. The sense of coherence questionnaire (SOC) A. Antonovsky’ego. Przegl Psychol. 1993;4:491-502. (In Polish.)

37. Juczyński Z. Measurements' tools in heath care promotion and psychology. In: Psychological test workshop. Warsaw: Polish Psychological Association; 2001. p. 119-22. (In Polish.)

38. Ying YW, Lee PA, Tsai JL. Predictors of depressive symptoms in Chinese American college students: parent and peer attachment, college challenges and sense of coherence. Am J Orthopsychiatry. 2007 Apr;77(2):316-23.

39. Von Bothmer MI, Fridlund B. Self-rated health among university students in relation to sense of coherence and other personality traits. Scand J Caring Sci. 2003 Dec;17(4):347-57.

40. Kivimäki M, Feldt T, Vahtera J, Nurmi JE. Sense of coherence and health: evidence from two cross-lagged longitudinal samples. Soc Sci Med. 2000 Feb;50(4):583-97.

41. Kuuppelomäki M, Utriainen P. A 3 year follow-up study of health care students' sense of coherence and related smoking, drinking and physical exercise factors. Int J Nurs Stud. 2003 May;40(4):383-8.

42. Piko BF, Luszczynska A, Gibbons FX, Teközel M. A culture-based study of personal and social influences of adolescent smoking. Eur J Public Health. 2005 Aug;15(4):393-8.

43. Gill JS. Reported levels of alcohol consumption and binge drinking within the UK undergraduate student population over the last 25 years. Alcohol Alcohol. 2002 Mar-Apr;37(2):109-20.

44. Tsuneji M, Sonoe M, Shigeji M, Osami K, Fumihiko J, Noriaki T, et al. A Study on health practice of university students. J Educ Health Sci. 1999;44(3):537-48. (In Japanese.)

45. Sek $\mathrm{H}$. Salutogenesis and fuctional competences of sense of coherence. In Sęk H, Pasikowski T, editors. Heath-stress resources. Abort the meaning of sense of coherence for heath. Poznań: Humaniora Foundation Publication; 2001. p. 23 -41. (In Polish.)

Received November 8, 2009 Accepted in revised form May 25, 2010 